\title{
Spatiotemporal variations of aridity index over the Belt and Road region under the $1.5^{\circ} \mathrm{C}$
}

\section{and $2.0^{\circ} \mathrm{C}$ warming scenarios}

\author{
ZHOU Jian ${ }^{1}$, JIANG Tong ${ }^{1}$, WANG Yanjun ${ }^{1},{ }^{*}$ SU Buda ${ }^{1,2}$, TAO Hui ${ }^{3}$, \\ QIN Jiancheng ${ }^{3,4}$, ZHAI Jianqing ${ }^{1,2}$
}

1. Collaboration Innovation Center on Forecast and Evaluation of Meteorological Disasters/Institute for Disaster Risk Management/School of Geographical Science, Nanjing University of Information Science \& Technology, Nanjing 210044, China;

2. National Climate Center, China Meteorological Administration, Beijing 100081, China;

3. State Key Laboratory of Desert and Oasis Ecology, Xinjiang Institute of Ecology and Geography, CAS, Urumqi 830011, China;

4. University of Chinese Academy of Sciences, Beijing 101408, China

\begin{abstract}
Aridity index reflects the exchanges of energy and water between the land surface and the atmosphere, and its variation can be used to forecast drought and flood patterns, which makes it of great significance for agricultural production. The ratio of potential evapotranspiration and precipitation is applied to analyse the spatial and temporal distributions of the aridity index in the Belt and Road region under the $1.5^{\circ} \mathrm{C}$ and $2.0^{\circ} \mathrm{C}$ global warming scenarios on the basis of outputs from four downscaled global climate models. The results show that: (1) Under the $1.5^{\circ} \mathrm{C}$ warming scenario, the area-averaged aridity index will be similar to that in 1986-2005 (around 1.58), but the changes vary spatially. The aridity index will increase by more than $5 \%$ in Central-Eastern Europe, north of West Asia, the monsoon region of East Asia and northwest of Southeast Asia, while it is projected to decrease obviously in the southeast of West Asia. Regarding the seasonal scale, spring and winter will be more arid in South Asia, and the monsoon region of East Asia will be slightly drier in summer compared with the reference period. While, West Asia will be wetter in all seasons, except winter. (2) Relative to 1986-2005, both areal averaged annual potential evapotranspiration and precipitation are projected to increase, and the spatial variation of aridity index will become more obvious as well at the $2.0^{\circ} \mathrm{C}$ warming level. Although the aridity index over the entire region will be maintained at approximately 1.57 as that in $1.5^{\circ} \mathrm{C}$, the index in Central-Eastern Europe, north of West Asia and Central Asia will grow rapidly at a rate of more
\end{abstract}

Received: 2018-12-20 Accepted: 2019-03-26

Foundation: National Key Research and Development Program of China, No.2017YFA0603701; Chinese-Pakistan cooperative project jointly funded by NSFC and PSF, No.41661144027; The CMA Climate Change Science Fund (CCSF 201722, 201810)

Author: Zhou Jian (1994-), Master Candidate, specialized in the climate change impact assessment. E-mail: zhoujian941208@163.com

*Corresponding author: Su Buda (1972-), Professor, E-mail: subd@cma.gov.cn 
than $20 \%$, while that in West Siberia, northwest of China, the southern part of South Asia and West Asia will show a declining trend. At the seasonal scale, the increase of the aridity index in Central-Eastern Europe, Central Asia, West Asia, South Asia and the northern part of Siberia in winter will be obvious, and the monsoon region in East Asia will be drier in both summer and autumn. (3) Under the scenario of an additional $0.5^{\circ} \mathrm{C}$ increase in global temperature from $1.5^{\circ} \mathrm{C}$ to $2.0^{\circ} \mathrm{C}$, the aridity index will increase significantly in Central Asia and north of West Asia but decrease in Southeast Asia and Central Siberia. Seasonally, the aridity index in the Belt and Road region will slightly increase in all other seasons except spring. Central Asia will become drier annually at a rate of more than $20 \%$. The aridity index in South Asia will increase in spring and winter, and that in East Asia will increase in autumn and winter. (4) To changes of the aridity index, the attribution of precipitation and potential evapotranspiration will vary regionally. Precipitation will be the major influencing factor over southern West Asia, southern South Asia, Central-Eastern Siberia, the non-monsoon region of East Asia and the border between West Asia and Central Asia, while potential evapotranspiration will exert greater effects over Central-Eastern Europe, West Siberia, Central Asia and the monsoon region of East Asia.

Keywords: $1.5^{\circ} \mathrm{C}$ and $2.0^{\circ} \mathrm{C}$ global warming scenarios; aridity index; spatial and temporal variations; the Belt and Road region

\section{Introduction}

As an important climate indicator, the aridity index is widely used to characterize the dry and wet levels of a region and is also applied to assess the impacts of climate change (Liu et al., 2013; Hao et al., 2014; Djaman et al., 2015; Wang et al., 2016). The aridity index can be quantified by the amount of precipitation, the ratio of potential evapotranspiration and precipitation, the relation between temperature and precipitation, the accumulated temperature and the heat balance equation (Cheng et al., 1996; Botzan et al., 1998; Arora, 2002; Meng et al., 2004). Amongst these, the ratio of potential evapotranspiration and precipitation is the most common method to measure regional aridity, which takes not only precipitation into account but also considers other variables (e.g., temperature, radiation, and wind speed); thus, this index can represent regional hydrological cycle patterns.

Global warming is expected to make the surface air drier and result in an increase of evaporation from water bodies (Chen et al., 2017). However, many regions of the world have observed decreasing pan evapotranspiration measurements in the last few decades (Peterson et al., 1995; Brutsaert et al., 1998; Roderick et al., 2007; Cong et al., 2008), while trends in global precipitation might be highly heterogeneous (Liu et al., 2013). Using the ratio of potential evapotranspiration and precipitation, studies have found that eastern China has become drier in the last century, with a more obvious trend after the 1960s (Zhang et al., 2016). A similar drying trend has been found in Turkey, Iran, Togo, eastern Greece, etc. (Türkeş, 2003; Nastos et al., 2013; Tabari et al., 2013; Djaman et al., 2015). While in northwest China, the aridity index indicates a significant decreasing trend over the last 30 years (Yin et al., 2005). The aforementioned observational results show that global warming leads to changes in the aridity index, and these changes vary spatially.

There is no doubt that the climate is warming (IPCC, 2013; IPCC, 2014). Climate change will accelerate the water cycle (Huntington, 2006; Oki et al., 2006), and the changing spatial and temporal patterns of precipitation, evapotranspiration, runoff and 
aridity conditions will further impact agricultural production and crop growth (Li et al., 2013; Chen et al., 2017; Cui et al., 2018). Previous studies point out that increasing aridity will occur in most tropical and mid-latitude regions in the 21 st century, which includes the subtropics, northern Africa, southern Africa and the Amazon, where precipitation change cannot keep pace with the increasing evaporative demand under the Representative Concentration Pathway (RCP) 8.5 scenario. At the same time, the aridity index might decrease in northwest China and tropical Africa (Feng et al., 2013; Lin et al., 2015). A drying trend is also projected to take place in western North America, Central America, and the Mediterranean by the end of this century under the double $\mathrm{CO}_{2}$ scenario (Fu et al., 2014). In addition to the high emissions scenario, it is necessary to project changes of the aridity index in low radiation forced situations under the background of the growing awareness of environmental and climate change protection.

China put forward an initiative of "The Belt and Road" in 2015 to strengthen the connection between the Asian Pacific and Europe and form a human community with shared destiny (Jiang et al., 2018; Liu et al., 2018; Lu et al., 2018). The Belt and Road region is the longest economic corridor around the world to date but has complex climatic conditions. Countries along the Belt and Road region have experienced increasingly severe climatic extremes in recent years and are highly vulnerable to climate change (Schilling et al., 2013; Su et al., 2016; Huang et al., 2017). Regional hydrological dynamics in a warming world are sensitive issues and have attracted considerable attention. In this study, the regional climate simulation capability of four global climate models (GCMs) is evaluated first based on observational data from the Climatic Research Unit (CRU) and then used to analyse the spatial temporal variation of the aridity index in the Belt and Road region at the $1.5^{\circ} \mathrm{C}$ and $2.0^{\circ} \mathrm{C}$ global warming levels. The main goal is to assess the trends of aridity index and drought/ flood risks under the scenario of an additional $0.5^{\circ} \mathrm{C}$ warming, so as to provide support for the development of climate change adaptation and mitigation strategies.

\section{Study area}

The Belt and Road region straddles Asia, Europe and Africa, and covers 65 countries with diverse natural environments. Eight types of climate dominate in this region, with both monsoon and continental climate characteristics and the regionally uneven distribution of water resources. Because the proportion of bare land and bush is higher in this region than the global average, the overall ecological environment is fragile (Wang et al., 2017). The Belt and Road region comprises over $50 \%$ of the world's population, and large variations in precipitation and evapotranspiration under a warming climate background might lead to serious consequences regarding water stress and agricultural output reduction.

According to the geographical divisions of the United Nations and Köppen climate classification, the Belt and Road region can be divided into nine sub-regions: Central-Eastern Europe, West Siberia, Central-Eastern Siberia, West Asia (Egypt included), Central Asia, South Asia, the non-monsoon region of East Asia, the monsoon region of East Asia and Southeast Asia (Figure 1). 


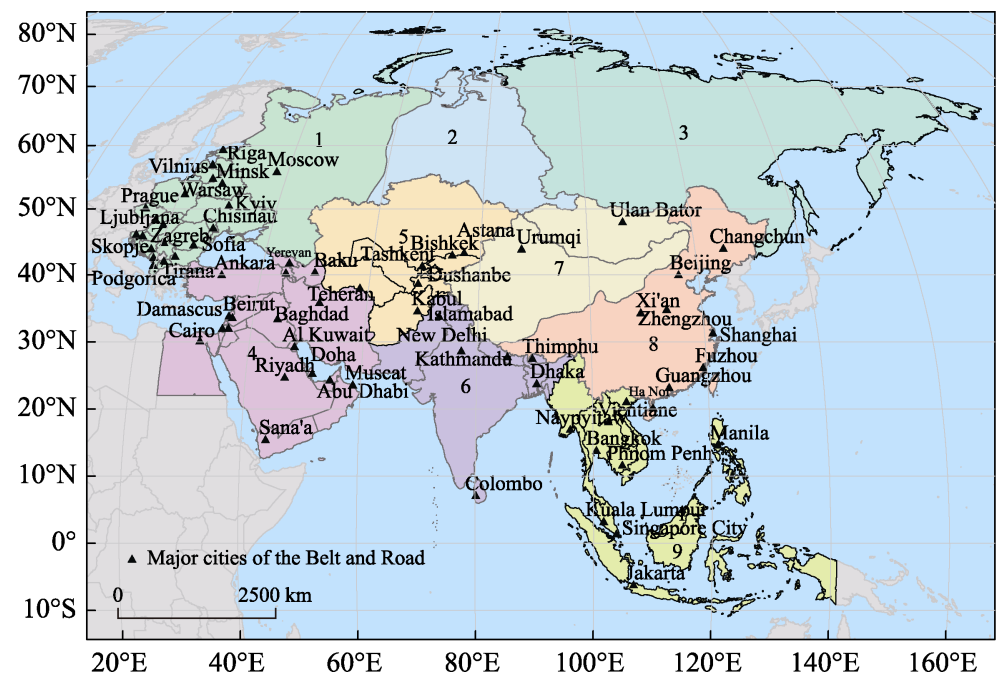

Figure 1 The Belt and Road sub-regions: 1. Central-Eastern Europe; 2. West Siberia; 3. Central-Eastern Siberia; 4. West Asia; 5. Central Asia; 6. South Asia; 7. Non-monsoon region of East Asia; 8. Monsoon region of East Asia; 9. Southeast Asia

\section{Data and methods}

\subsection{Data}

The Climatic Research Unit (CRU) datasets include monthly precipitation and potential evapotranspiration during 1961-2017. These datasets for the period 1961-2005 when matches the historical period of climate simulation data are used to evaluate the simulation capacity of the GCMs. The CRU is based on more than 4000 meteorological stations around the world and covers the land areas of the Earth at a spatial resolution of $0.5^{\circ} \times 0.5^{\circ}$ (Harris et al., 2014). Observational data in this paper are selected from the CRU datasets that involve 25,167 grids in the Belt and Road region.

Climate simulation data are from four GCMs (GFDL-ESM2M, HadGEM2-ES, IPSLCM5A-LR and MIROC5) in the Coupled Model Intercomparison Project Phase 5 (Table 1). The model outputs include the daily mean, maximum and minimum temperature, precipitation, relative humidity, wind speed, etc, for the historical period 1961-2005 and future projections under the RCP 2.6, 4.5, 6.0 and 8.5 scenarios. All model outputs have been downscaled to a grid with a $0.5^{\circ} \times 0.5^{\circ}$ resolution and bias corrected to ensure statistical agreement with the observational data in the Inter-Sectoral Impact Model Intercomparison Project Phase two (Hempel et al., 2013; Warszawski et al., 2014; Frieler et al., 2017).

Table 1 Basic information on the four global climate models (GCMs)

\begin{tabular}{llc}
\hline \multicolumn{1}{c}{ Climate model } & \multicolumn{1}{c}{ Research institute } & Original horizontal resolution \\
\hline GFDL-ESM2M & Geophysical Fluid Dynamics Laboratory & $144 \times 90$ \\
HadGEM2-ES & Hadley Centre for Climate Prediction and Research & $192 \times 145$ \\
IPSL-CM5A-LR & L'Institut Pierre-Simon Laplace & $96 \times 96$ \\
MIROC5 & Atmosphere and Ocean Research Institute & $256 \times 128$ \\
\hline
\end{tabular}

Note: Horizontal resolution indicates the number of longitudinal grids $\times$ the number of latitudinal grids. 


\subsection{Methods}

\subsubsection{Aridity index}

The aridity index in this study is deduced by the ratio of potential evapotranspiration and precipitation. The greater the Aridity Index is, the more dryer the climate. Areas where the aridity index is less than 1 are regarded as humid regions (Ponce et al., 2000). In contrast, areas with aridity index values exceeding 1 are those where the regional evaporative demand exceeds the water supply. In detail, the aridity index in semi-humid regions is typically between 1 and 1.5; in semi-arid regions, it is between 1.5 and 4, and in arid regions it is more than 4 (Zheng et al., 2010; Zheng et al., 2013; Huang et al., 2016).

$$
\begin{gathered}
A I=\frac{E T_{P}}{P} \\
E T_{P}=\frac{0.408 \Delta\left(R_{n}-G\right)+r \frac{900}{T+273} U_{2}\left(e_{s}-e_{a}\right)}{\Delta+r\left(1+0.34 U_{2}\right)}
\end{gathered}
$$

where $A I$ indicates the aridity index; $P$ represents precipitation $(\mathrm{mm}) ; E T_{P}$ represents potential evapotranspiration $(\mathrm{mm})$ and is calculated based on the Penman-Monteith formula recommended by the United Nations Food and Agriculture Organization (Allen, 1998); $\Delta$ represents the slope of the temperature-saturation vapor pressure curve $\left(\mathrm{kPa}^{\circ} \mathrm{C}^{-1}\right) ; R_{n}$ represents the net surface radiation $\left(\mathrm{MJ} \cdot \mathrm{m}^{-2} \cdot \mathrm{d}^{-1}\right) ; G$ represents the soil heat flux $\left(\mathrm{mm} \cdot \mathrm{d}^{-1}\right)$ and is usually neglected when calculating the daily $E T_{P} ; r$ means the psychrometric constant $(\mathrm{kPa}$ $\left.{ }^{\circ} \mathrm{C}^{-1}\right) ; T$ represents the temperature $\left({ }^{\circ} \mathrm{C}\right) ; U_{2}$ represents the wind speed at a height of $2 \mathrm{~m}$ $\left(\mathrm{m} \cdot \mathrm{s}^{-1}\right)$; and $e_{s}$ and $e_{a}$ represent the saturation vapor pressure and actual water vapor pressure $(\mathrm{kPa})$, respectively.

\subsubsection{Horizons of the $1.5^{\circ} \mathrm{C}$ and $2.0^{\circ} \mathrm{C}$ global warming}

The global average temperature during the reference period (1986-2005) increased by $0.61{ }^{\circ} \mathrm{C}$ compared to the pre-industrial period in 1850-1900 (IPCC, 2013). Extra $0.89^{\circ} \mathrm{C}$ and $1.39^{\circ} \mathrm{C}$ increases of temperature will lead to global warming increases of $1.5^{\circ} \mathrm{C}$ and $2.0^{\circ} \mathrm{C}$, respectively, relative to the pre-industrial level. Previous studies have predicted that a global warming of $1.5^{\circ} \mathrm{C}$ is expected to occur in 2020-2039 under the RCP 2.6 scenario, and the temperature will increase $2.0^{\circ} \mathrm{C}$ in 2040-2059 under the RCP 4.5 scenario (Warszawski et al., 2014; Schleussner et al., 2016; Chen et al., 2017; Liu et al., 2017; Su et al., 2017; Sun et al., 2017; Wang et al., 2017).

\subsubsection{Sensitivity analysis}

The sensitivity of the aridity index to potential evapotranspiration and precipitation can be evaluated as follows:

$$
S_{x_{i}}=\frac{A I\left(x_{i}\right)-A I_{0}}{A I_{0}} \times 100 \%
$$

where $x_{i}$ represents the variable that denotes potential evapotranspiration or precipitation in this paper, $S_{x_{i}}$ represents the sensitivity coefficient of the aridity index related to $x_{i}, A I_{0}$ represents the original aridity index, and $A I\left(x_{i}\right)$ represents the aridity index with the change 
in the specified variable. When the sensitivity of potential evapotranspiration to the aridity index is calculated, precipitation remains unchanged, and vice versa.

\section{Results}

\subsection{Comparison of GCM simulations with observations}

The inter-annual distributions of precipitation and potential evapotranspiration simulated by GCMs over the Belt and Road region during 1961-2005 are compared with the observation data (Figure 2). The GCMs are able to capture the monthly dynamics of regional precipitation very well, with seasonal fluctuations of less precipitation in winter and more precipitation in summer. Although the multi-model ensemble mean is slightly higher than the observed precipitation, gap of each month is less than $3 \mathrm{~mm}$ (Figure 2a). Meanwhile, the inter-annual distribution of potential evapotranspiration over the Belt and Road region by the GCM ensemble also matches the observations. Despite the fact that the GCM ensemble overestimates potential evapotranspiration by approximately $10 \mathrm{~mm}$ in summer, the deviation in potential evapotranspiration is less than $8 \%$ throughout the year (Figure $2 \mathrm{~b}$ ).
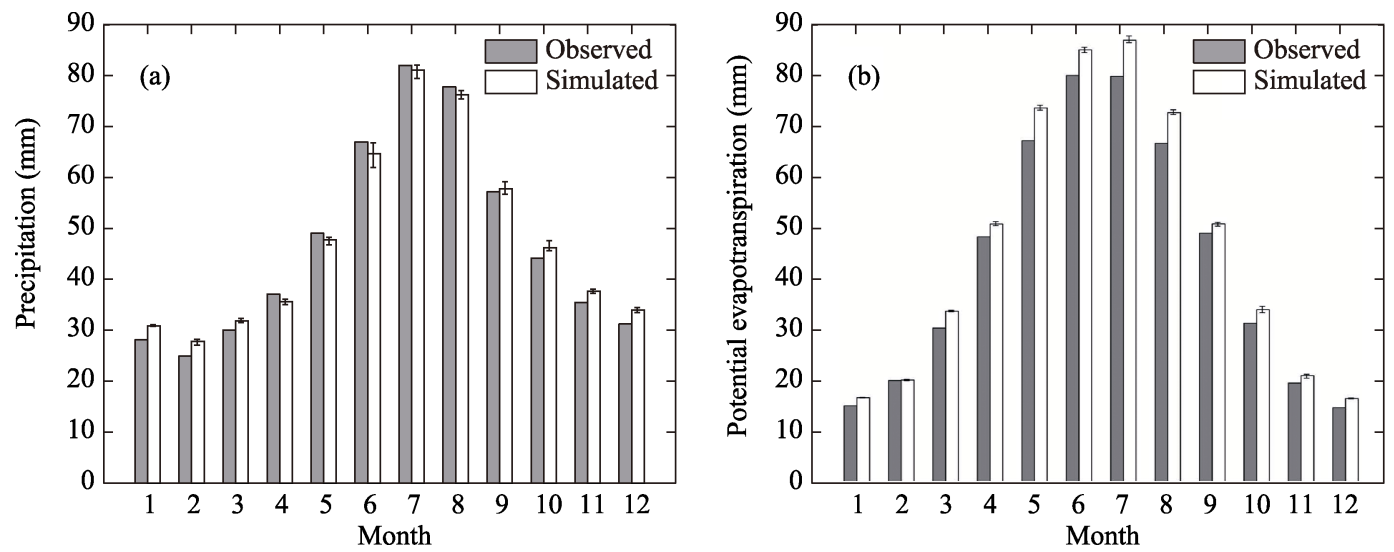

Figure 2 Comparison of GCM ensemble mean with observation in the Belt and Road region for 1961-2005: multi-year averaged monthly precipitation (a) and potential evapotranspiration (b)

Note: The upper and lower limits represent the range of climate models. The same applies to Figures 4 and 6.

Spatial distributions of annual precipitation and potential evapotranspiration over the Belt and Road region for 1961-2005 are shown in Figure 3 based on both observation and multi-model ensemble mean. The spatial correlation coefficient between the simulated and observed precipitation patterns reaches 0.96 , which is significant at the 0.05 level, with high levels of precipitation in Southeast and South Asia and that are rare in West Asia and the non-monsoon region of East Asia (Figures 3a-3b). For annual potential evapotranspiration, the spatial correlation coefficient between the simulation and observation is approximately 0.98, with higher values in West Asia, South Asia and the southern part of Central Asia and a decrease from southwest to northeast (Figures 3c-3d).

\subsection{Projection of precipitation and potential evapotranspiration}

The variation of the aridity index is closely related to changes of precipitation and poten- 

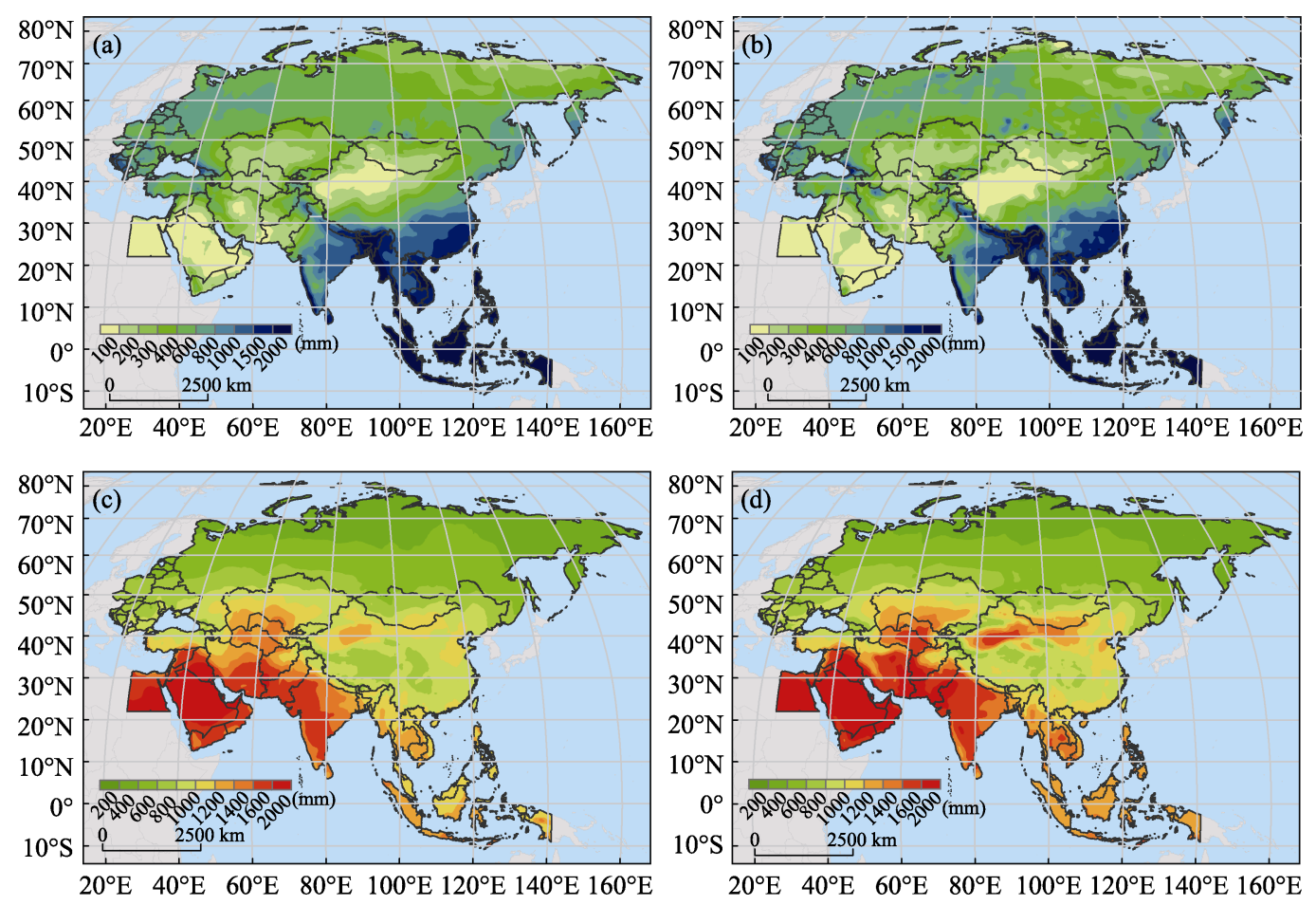

Figure 3 Spatial distributions of annual precipitation and potential evapotranspiration for 1961-2005: observed and simulated precipitation (a-b); observed and simulated potential evapotranspiration (c-d)

tial evapotranspiration. In the 1986-2005 reference period, area-averaged annual precipitation over the Belt and Road region is approximately $574 \mathrm{~mm}$ by the ensemble, with model values ranging from $568 \mathrm{~mm}$ to $580 \mathrm{~mm}$. Relative to the reference period, precipitation will increase by $5.3 \%$ and reach $605 \mathrm{~mm}(600-613 \mathrm{~mm})$ under a global warming scenario of $1.5^{\circ} \mathrm{C}$, with the largest growth of $25 \%$ in West Asia. Meanwhile, precipitation will slightly decrease in Central Asia, Central-Eastern Europe and Southeast Asia. Under the $2.0^{\circ} \mathrm{C}$ warming scenario, area averaged annual precipitation will further increase to $620 \mathrm{~mm}(608-635 \mathrm{~mm})$, with a remarkably increase of over $15 \%$ in West Asia, the non-monsoon region of East Asia and Central-Eastern Siberia. Decreased precipitation will occur in Central-Eastern Europe, Central Asia and north of West Asia, with the largest decrease of more than 5\% (Figures 4a and $5 a-5 b)$.
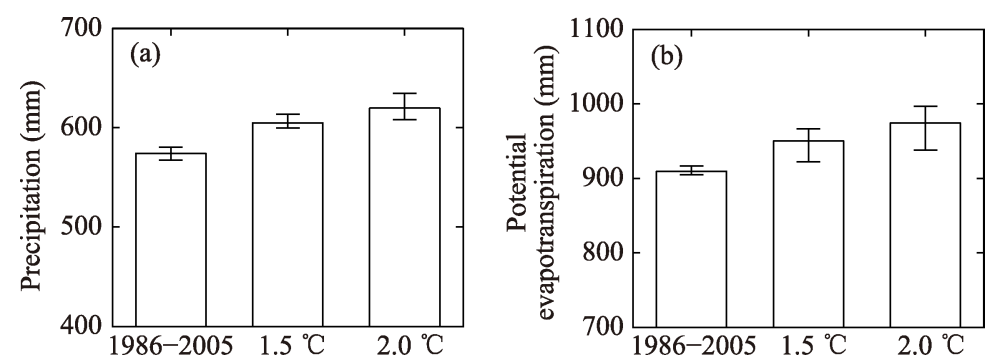

Figure 4 Comparison of precipitation (a) and potential evapotranspiration (b) in $1986-2005,1.5^{\circ} \mathrm{C}$ and $2.0^{\circ} \mathrm{C}$ global warming levels over the Belt and Road region 
Potential evapotranspiration is approximately $910 \mathrm{~mm}(905-912 \mathrm{~mm})$ over the Belt and Road region in 1986-2005. Under the global warming scenario of $1.5^{\circ} \mathrm{C}$, potential evapotranspiration will reach $950 \mathrm{~mm}(922-967 \mathrm{~mm})$, with the fastest growth of more than $10 \%$ in Central-Eastern Europe and a slight decrease in Southeast Asia. The increase of potential evapotranspiration will be more extensive under the $2.0^{\circ} \mathrm{C}$ warming scenario. The area-averaged potential evapotranspiration will increase to $974 \mathrm{~mm}(938-997 \mathrm{~mm})$, with an increase of more than 10\% in Central-Eastern Europe, Central-Eastern Siberia and the monsoon region of East Asia relative to the reference period (Figures $4 b$ and $5 c-5 d$ ).
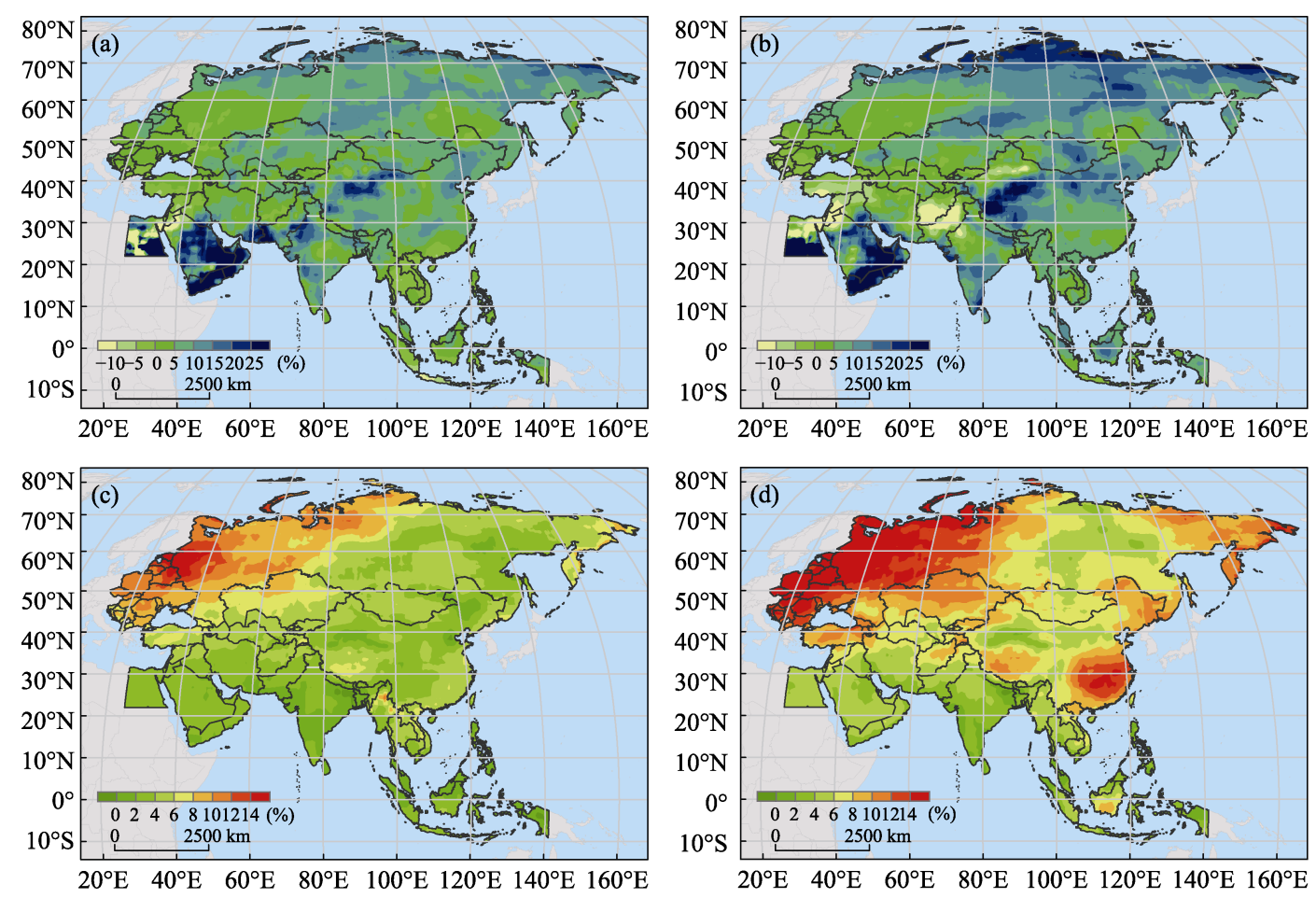

Figure 5 Changes in precipitation (a-b) and potential evapotranspiration (c-d) under the $1.5^{\circ} \mathrm{C}$ and $2.0^{\circ} \mathrm{C}$ global warming scenarios relative to the reference period over the Belt and Road region: (a) and (c) show the changes in precipitation and potential evapotranspiration under the $1.5^{\circ} \mathrm{C}$ scenario compared to the reference period; (b) and (d) show the changes in precipitation and potential evapotranspiration under the $2.0^{\circ} \mathrm{C}$ scenario compared to the reference period

\subsection{Projection of the aridity index under the $1.5^{\circ} \mathrm{C}$ and $2.0^{\circ} \mathrm{C}$ warming scenarios}

\subsubsection{Changes in the annual aridity index}

In 1986-2005, the annual aridity index in the Belt and Road region was approximately 1.58 (1.57-1.61). West Asia, Central Asia and the non-monsoon region of East Asia can be considered as arid areas, with the highest aridity index of more than 10 in West Asia. South Asia belongs to a semi-arid area, while Central-Eastern Europe, Central-Eastern Siberia and the monsoon region of East Asia are semi-humid. Southeast Asia is the wettest area in the Belt and Road region, and the aridity index is only about $0.57(0.56-0.58)$ (Figures 6 and $7 \mathrm{a}$ ). With global warming, the aridity index in the Belt and Road region will maintain at 1.57 due 


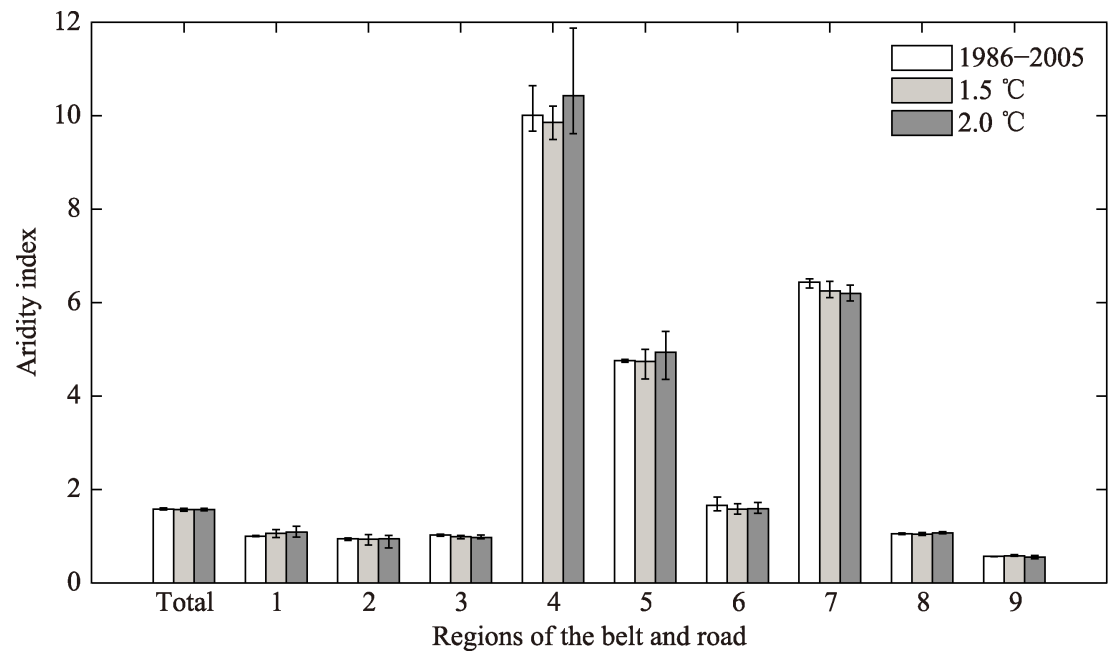

Figure 6 Annual aridity index changes in the Belt and Road region under the $1.5^{\circ} \mathrm{C}$ and $2.0^{\circ} \mathrm{C}$ global warming scenarios

Note: Numbers (1-9) denote different areas of the Belt and Road region marked in Figure 1. The same applies to Figure 8 .

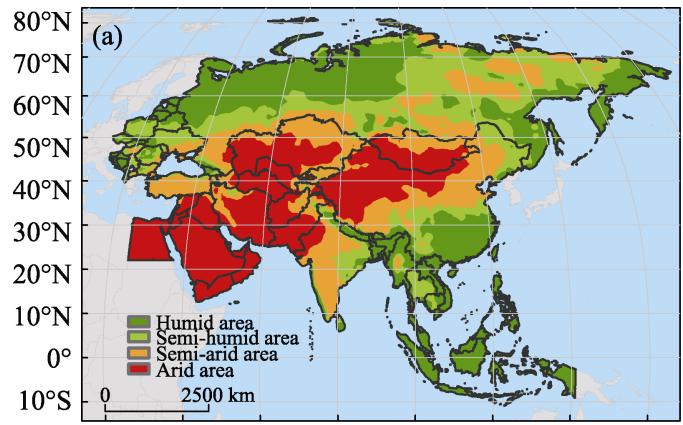

$20^{\circ} \mathrm{E} \quad 40^{\circ} \mathrm{E} \quad 60^{\circ} \mathrm{E} \quad 80^{\circ} \mathrm{E} 100^{\circ} \mathrm{E} 120^{\circ} \mathrm{E} 140^{\circ} \mathrm{E} 160^{\circ} \mathrm{E}$

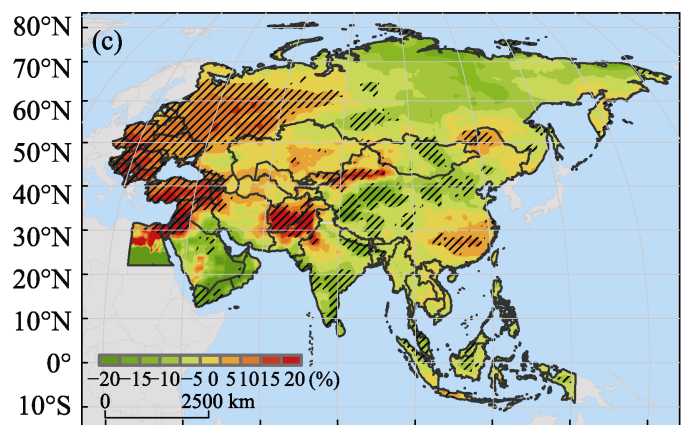

$20^{\circ} \mathrm{E} \quad 40^{\circ} \mathrm{E} \quad 60^{\circ} \mathrm{E} \quad 80^{\circ} \mathrm{E} \quad 100^{\circ} \mathrm{E} 120^{\circ} \mathrm{E} 140^{\circ} \mathrm{E} 160^{\circ} \mathrm{E}$

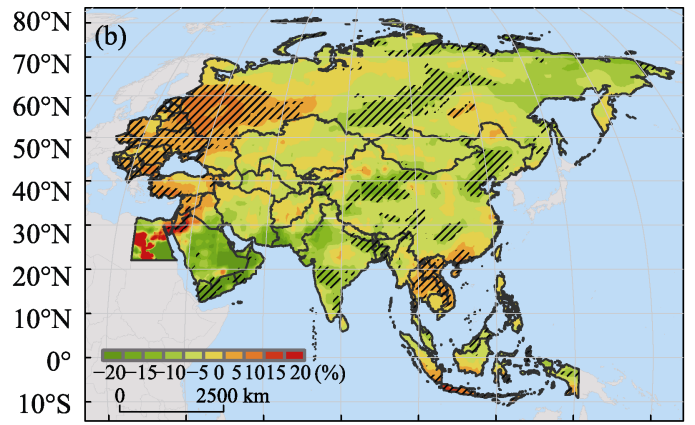

$20^{\circ} \mathrm{E} \quad 40^{\circ} \mathrm{E} \quad 60^{\circ} \mathrm{E} \quad 80^{\circ} \mathrm{E} \quad 100^{\circ} \mathrm{E} 120^{\circ} \mathrm{E} 140^{\circ} \mathrm{E} 160^{\circ} \mathrm{E}$

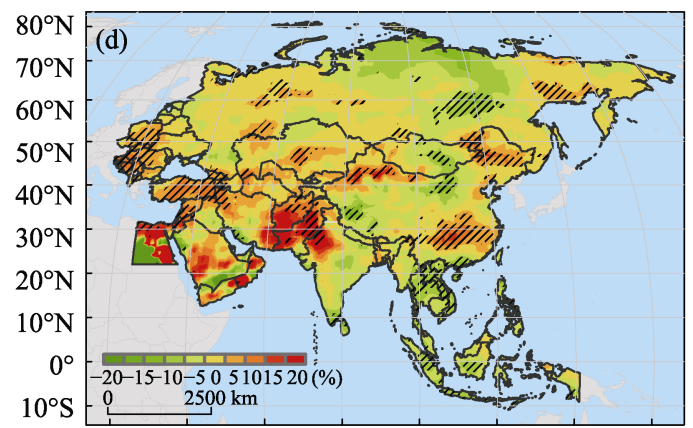

$20^{\circ} \mathrm{E} \quad 40^{\circ} \mathrm{E} \quad 60^{\circ} \mathrm{E} \quad 80^{\circ} \mathrm{E} \quad 100^{\circ} \mathrm{E} 120^{\circ} \mathrm{E} 140^{\circ} \mathrm{E} 160^{\circ} \mathrm{E}$

Figure 7 Spatial distribution of the aridity index in the Belt and Road region: (a) in 1986-2005; (b) changes in the $1.5^{\circ} \mathrm{C}$ with relative to the reference period; (c) changes in the $2.0^{\circ} \mathrm{C}$ with relative to the reference period; $(\mathrm{d})$ changes in the $2.0^{\circ} \mathrm{C}$ with relative to the $1.5^{\circ} \mathrm{C}$

Note: Dashes in the figures represent areas with significant changes at $p<0.1$. This also applies to Figure 9.

to the simultaneous increases in precipitation and potential evapotranspiration. Under the $1.5^{\circ} \mathrm{C}$ global warming scenario, the aridity index in Central-Eastern Europe, north of West Asia, 
south of East Asia and northwest of Southeast Asia will rise rapidly at a rate of over 5\% compared to 1986-2005. In contrast, the aridity index will decline in southeast of West Asia, South Asia and Central-Eastern Siberia (Figure $7 \mathrm{~b}$ ). Under a global warming scenario of $2.0^{\circ} \mathrm{C}$, the aridity index in Central-Eastern Europe and north of West Asia will further grow by $15 \%$ relative to the 1986-2005 period. In addition, the aridity index in Central Asia will also increase rapidly. Meanwhile, the decreasing trend of the aridity index in Central-Eastern Siberia will be extended (Figure 7c).

Relative to the $1.5^{\circ} \mathrm{C}$ level, the spatial distribution of the aridity index with an additional $0.5^{\circ} \mathrm{C}$ of global warming in the Belt and Road region will change substantially. Spatially, the aridity index along the borders of Central Asia, South Asia and West Asia will increase significantly at a rate of approximately $15 \%$, followed by Central-Eastern Europe and the monsoon region of East Asia, where the increase will be above 5\%. Meanwhile, the aridity index will decrease by approximately $5 \%$ in the west of Central-Eastern Siberia and Southeast Asia (Figure 7d).

\subsubsection{Changes of the seasonal aridity index}

Area averaged aridity index values in the Belt and Road region for four seasons are shown in Figure 8. The seasonal aridity index during the reference period is approximately 2.23 (2.22-2.28), 1.77 (1.73-1.82), 1.20 (1.18-1.23), and 0.93 (0.92-0.94) for spring, summer, autumn and winter, respectively. Under the $1.5^{\circ} \mathrm{C}$ scenario, the aridity index is projected to decrease appreciably, except during the spring season. However, spatial changes of the aridity index will vary in amplitude. Central-Eastern Europe and West Siberia are projected to be drier throughout the year, but the non-monsoon region of East Asia will become wetter. Under the $2.0^{\circ} \mathrm{C}$ warming scenario, the aridity index is projected to increase
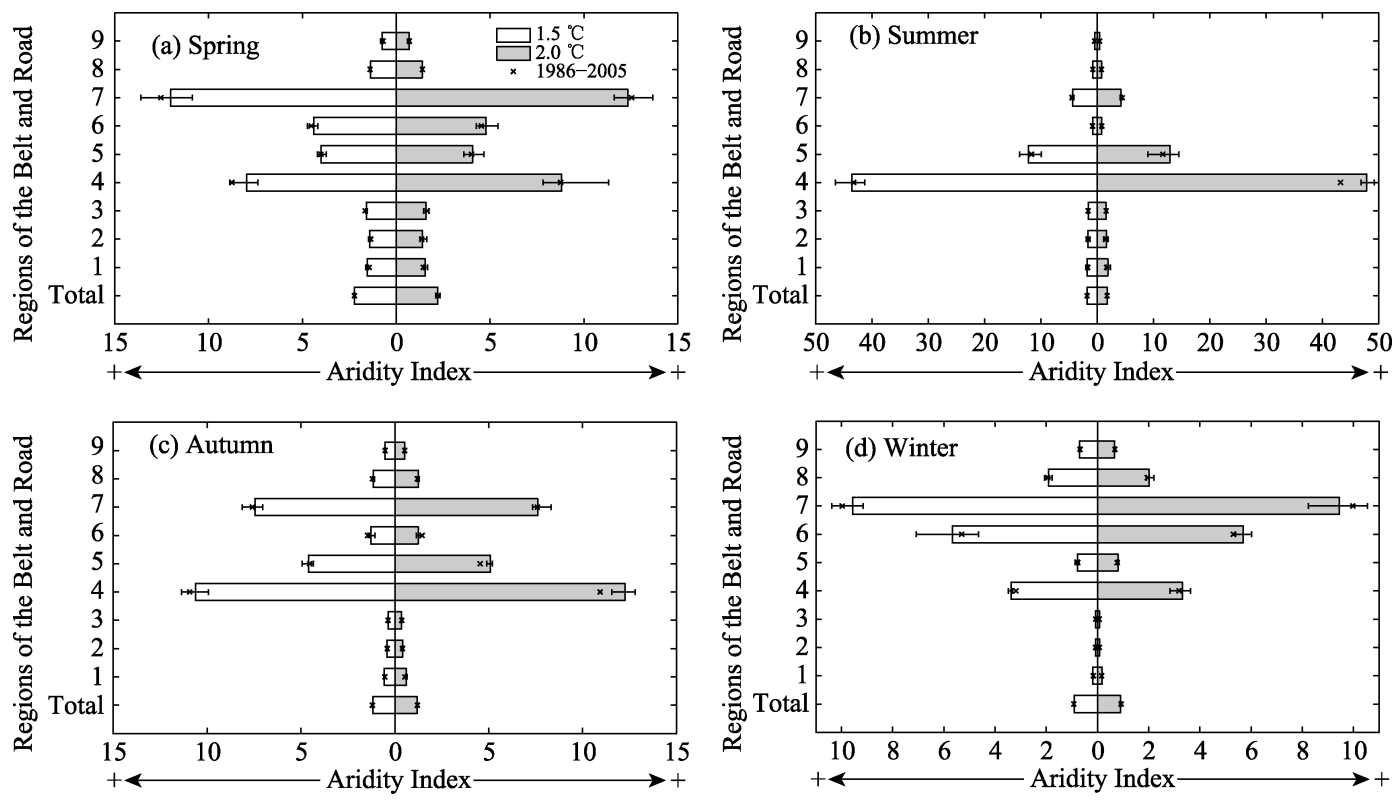

Figure 8 Seasonal aridity index changes in the Belt and Road region under the $1.5^{\circ} \mathrm{C}$ and $2.0^{\circ} \mathrm{C}$ global warming scenarios: (a) spring, (b) summer, (c) autumn, and (d) winter

Note: The black mark $(\times)$ above the bars represents the multi-model ensemble mean in 1986-2005. 
by $0.57 \%$ up to $1.78(1.69-1.88)$ in summer compared with that in 1986-2005, but the changes will be slight in other seasons. In addition to Central-Eastern Europe and West Siberia, the drying trend also covers West Asia, Central Asia and the monsoon region of East Asia.

Under the $1.5^{\circ} \mathrm{C}$ global warming scenario, the aridity index in the northwestern part of West Asia, south of South Asia and northwest Southeast Asia will increase more than that in other regions during the spring season by more than $20 \%$ relative to the reference period, followed by an increase of about $10 \%-15 \%$ in Central-Eastern Europe. Meanwhile, the aridity index will decrease by approximately $15 \%$ in the eastern part of West Asia and the western part of the monsoon region in East Asia. In summer, the greatest increase of the aridity index will occur in Central Asia, followed by the northwest region of Southeast Asia and Central-Eastern Europe. In contrast, the aridity index will decrease sharply in the eastern portion of West Asia. In autumn, spatial pattern of changes in the aridity index will be similar to those in summer, except for a $15 \%$ decrease in South Asia. In winter, the dryness trend will be significant in the eastern part of South Asia, southwestern part of the monsoon region of East Asia, the northern region of West Asia and Central-Eastern Europe, where the aridity index will increase by more than $20 \%$ (Figures 9a1-d1).

In the $2.0^{\circ} \mathrm{C}$ warming level, dryness will be obvious in Central-Eastern Europe and the northwestern part of South Asia in spring, with the aridity index increasing by more than $15 \%$ compared with that in 1986-2005. In summer and autumn, the aridity index will increase rapidly in the west but slowly in the southeastern part of the monsoon region of East Asia. Central Asia, Central-Eastern Europe and the northern region of West Asia will present significant dryness trends, with an increase of the aridity index over $20 \%$, while South Asia will experience a wetter trend. In winter, the aridity index in Central-Eastern Europe, South Asia, Central Asia, the northern region of Central Asia, West Siberia and the northern region of Central-Eastern Siberia will increase by more than $20 \%$ but decrease in the non-monsoon region of East Asia, northwest of Southeast Asia and south of West Asia by approximately $20 \%$ (Figures 9a2-d2).

For an additional $0.5^{\circ} \mathrm{C}$ warming scenario from $1.5^{\circ} \mathrm{C}$ to $2.0^{\circ} \mathrm{C}$, the aridity index will increase by more than $20 \%$ along the borders of Central Asia, South Asia and West Asia, while in the northwest of Southeast Asia and northeast of South Asia, the aridity index will decrease by about $15 \%-20 \%$ in spring season. In summer, the extent of dryness will further expand, and the aridity index in Central-Eastern Europe, Central Asia and most of West Asia will increase by more than $20 \%$. In autumn, the aridity index will increase in the majority of the Belt and Road region, which will be most obvious in Central Asia, West Asia, northwest of South Asia, and all of East Asia. In winter, the aridity index will significantly increase by more than $20 \%$ in the western area of South Asia, southeast coastal of the monsoon region of East Asia, north of East Siberia and northwest of Central-Eastern Siberia, but it will decrease by $10 \%-20 \%$ in the northwest of South Asia and west of Central-Eastern Siberia (Figures 9a3-d3).

\subsubsection{Attribution to aridity index changes}

Figure 10 shows the spatial changes in the aridity index for the $1.5^{\circ} \mathrm{C}$ and $2.0^{\circ} \mathrm{C}$ global warming scenarios due to changes in precipitation (Figures $10 \mathrm{a}$ and $10 \mathrm{c}$, respectively) and 

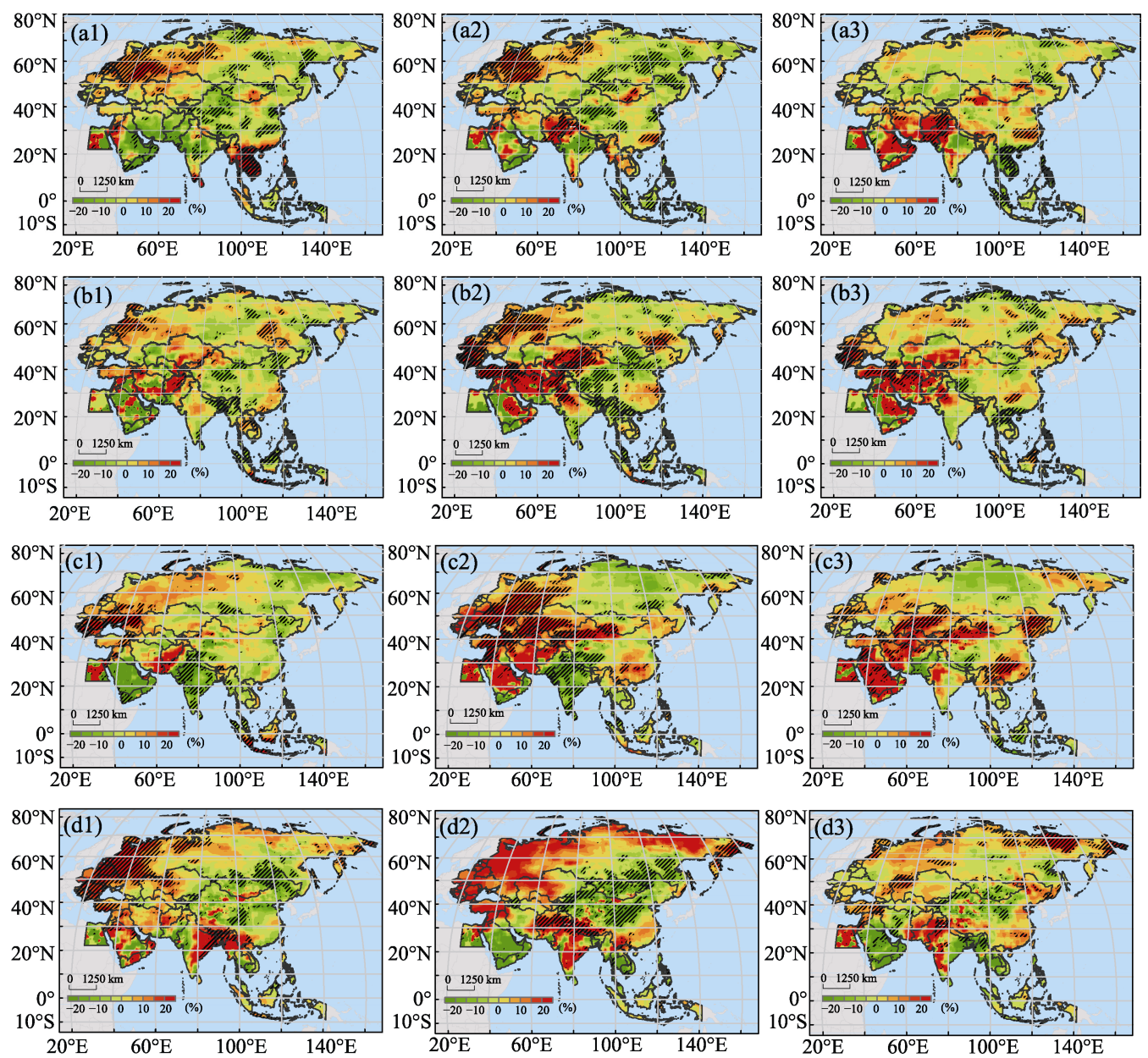

Figure 9 Relative changes of the seasonal aridity index under the $1.5^{\circ} \mathrm{C}$ and $2.0^{\circ} \mathrm{C}$ warming scenarios: (a) spring, (b) summer, (c) autumn, (d) and winter. (1-3) denote the $1.5^{\circ} \mathrm{C}$ scenario relative to the reference period, the $2.0^{\circ} \mathrm{C}$ scenario relative to the reference period, and the $2.0^{\circ} \mathrm{C}$ scenario relative to the $1.5^{\circ} \mathrm{C}$ scenario, respectively

potential evapotranspiration (Figures $10 \mathrm{~b}$ and $10 \mathrm{~d}$, respectively).

The sensitivity analyses show that at the $1.5^{\circ} \mathrm{C}$ warming level, precipitation play a more important role than potential evapotranspiration in the southern region of West Asia, South Asia, Central-Eastern Siberia and the non-monsoon region of East Asia, where the attribution of precipitation will be up between $-20 \%$ and $-8 \%$ and potential evapotranspiration will be around $0-8 \%$, together conspire the decrease of aridity index of about $0-20 \%$. However, in Central-Eastern Europe, West Siberia, Central Asia and the monsoon region of East Asia, an increase of potential evapotranspiration will attribute largely to the increasing aridity index with amount of $8 \%-20 \%$, and attribution of precipitation will be from $-8 \%$ to $-4 \%$. Major differences under the $2.0^{\circ} \mathrm{C}$ warming scenario relative to the $1.5^{\circ} \mathrm{C}$ scenario are found along the border of South Asia and Central Asia, where the drying trend could be explained mainly by the decrease in precipitation. 


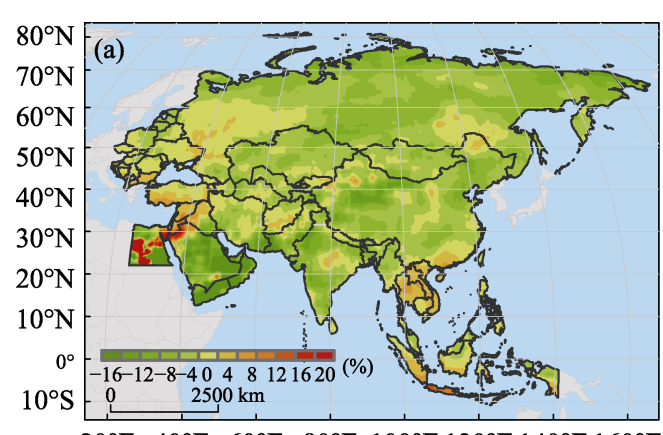

$20^{\circ} \mathrm{E} \quad 40^{\circ} \mathrm{E} \quad 60^{\circ} \mathrm{E} \quad 80^{\circ} \mathrm{E} 100^{\circ} \mathrm{E} 120^{\circ} \mathrm{E} 140^{\circ} \mathrm{E} 160^{\circ} \mathrm{E}$

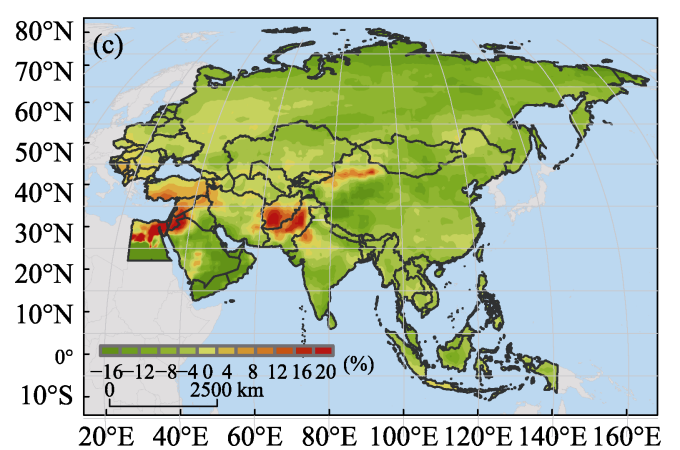

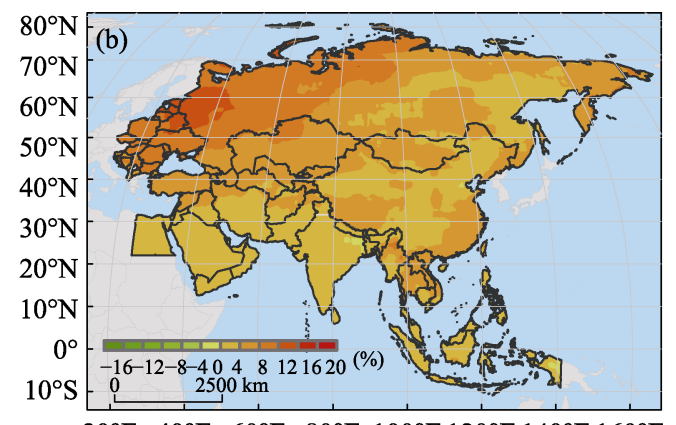

$20^{\circ} \mathrm{E} 40^{\circ} \mathrm{E} 60^{\circ} \mathrm{E} \quad 80^{\circ} \mathrm{E} 100^{\circ} \mathrm{E} 120^{\circ} \mathrm{E} 140^{\circ} \mathrm{E} 160^{\circ} \mathrm{E}$

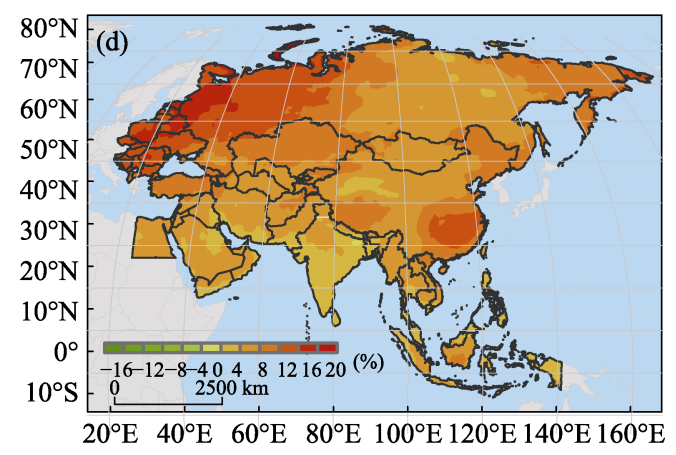

Figure 10 Changes in the aridity index attributable to precipitation (a, c) and potential evapotranspiration (b, d) under the $1.5^{\circ} \mathrm{C}$ scenario $(\mathrm{a}, \mathrm{b})$ and $2.0^{\circ} \mathrm{C}$ scenario (c, d) relative to $1986-2005$

\section{Conclusions and discussion}

\subsection{Conclusions}

The aridity index can represent the distribution of the energy balance and water circulation on the surface of the earth. Its spatial and temporal changes reflect regional droughts and floods. Based on four GCMs, changes of the aridity index over the Belt and Road region are analysed using the Penman-Monteith formula based potential evapotranspiration and precipitation. The following conclusions are drawn in this paper:

(1) In 1986-2005, the area averaged annual potential evapotranspiration and precipitation are about $910 \mathrm{~mm}$ and $574 \mathrm{~mm}$, respectively, and the aridity index over the Belt and Road region is approximately 1.58 . Spatially, the most arid region lies in the middle and low-latitude Eurasia, such as West Asia, Central Asia and the non-monsoon region of East Asia, while Central-Eastern Europe, West Siberia, the monsoon region of East Asia and Southeast Asia are relatively humid. Note that South Asia belongs to a semi-arid area, with distinct dry and wet seasons.

(2) Under the $1.5^{\circ} \mathrm{C}$ global warming scenario, with a $4.5 \%$ increase of annual potential evapotranspiration and a $5.3 \%$ increase in annual precipitation, the aridity index over the Belt and Road region will change slightly compared with that in 1986-2005 but with spatially distinct variability. The aridity index in Central-Eastern Europe, north of West Asia, south of the monsoon region in East Asia and northwest of Southeast Asia will increase by more than 5\%, but it will significantly decrease in Central-Eastern Siberia. For the seasonal 
scale, changes in the aridity index in winter will be more obvious in Central-Eastern Europe, with increases over $20 \%$, but the index in spring and summer will be relatively flat. The spring and winter seasons in South Asia are expected to become drier, and the dryness trend is also expected in the monsoon region of East Asia in summer, while West Asia is expected to become wetter than before, except during winter.

(3) In the $2.0^{\circ} \mathrm{C}$ warming level, potential evapotranspiration and precipitation will increase further, with rates of $7.1 \%$ and $7.9 \%$, respectively, relative to those in 1986-2005. Although the aridity index over the Belt and Road region will still be approximately 1.57, the spatial variation will be more obvious. Central-Eastern Europe, north of West Asia and Central Asia will become drier, with an over $20 \%$ growth of the aridity index, while Central-Eastern Siberia, the southern part of South Asia and the southeastern part of West Asia might be in a wetness trend. Seasonally, the drying trend will be extensive in autumn and winter, covering Central-Eastern Europe, Central Asia and West Asia. And the trend will even extend towards South Asia, eastern Siberia and north of Central-Eastern Siberia in winter. Differences between the dry and wet seasons in South Asia will be more pronounced, and the monsoon region in East Asia will be drier than it was previously in summer and autumn. The non-monsoon East Asia region will get wetter (excluding autumn).

(4) Compared with the $1.5^{\circ} \mathrm{C}$ global warming scenario, change of the area-averaged aridity index over the Belt and Road region is not distinct in the $2.0^{\circ} \mathrm{C}$ warming scenario, but significant dryness in Central Asia and north of West Asia and wetness in Southeast Asia and Central Siberia are expected. Seasonally, an increasing trend of the aridity index in Central-Eastern Europe will be continuous, especially in summer. The aridity index will increase at a rate of over $20 \%$ in all four seasons in Central Asia, and the increase is obvious in autumn and winter in the monsoon region of East Asia. South Asia will experience intense aridity in spring and winter, but the aridity index will decrease in West Asia during winter.

\subsection{Discussion}

It can be seen that the increase of the aridity index over the Belt and Road region under the $2.0^{\circ} \mathrm{C}$ warming scenario will be more severe than that under the $1.5^{\circ} \mathrm{C}$ scenario, especially in Central-Eastern Europe, north of West Asia, Central Asia, the monsoon region of East Asia and South Asia in summer and autumn. As a result, crop yields might be reduced due to water shortages. Our findings are consistent with the drier trends of the aridity index over the Mediterranean, Central Asia, monsoon region of East Asia and a wetter trend in the northwest of China found by previous projection studies (Fu et al., 2014; Lin et al., 2015). In addition, this study shows more detailed variation characteristics based on downscaled climate models by identifying the increasing dryness in northeast of West Asia, northwest of the non-monsoon region East Asia and elsewhere. Precipitation is the most important factor determining the aridity index in southern West Asia, southern South Asia, Central-Eastern Siberia, the non-monsoon region of East Asia and along the border of West Asia and Central Asia, while potential evapotranspiration is the key factor influencing the aridity index in Central-Eastern Europe, West Siberia, Central Asia and the monsoon region of East Asia. However, many meteorological variables affect potential evapotranspiration; thus, it is necessary to conduct more thorough studies to analyse their contributions to the changes of aridity index in detail. 


\section{References}

Allen R G, 1998. Crop evapotranspiration: Guidelines for computing crop water requirements. FAO Irrigation \& Drainage Paper, 56.

Arora V K, 2002. The use of the aridity index to assess climate change effect on annual runoff. Journal of Hydrology, 265(1): 164-177.

Botzan T, Mariano M, Necula A, 1998. Modified De Martonne aridity index: Application to the Napa Basin, California. Physical Geography, 19(1): 55-70.

Brutsaert W, Parlange M B, 1998. Hydrologic cycle explains the evaporation paradox. Nature, 396(6706): 30.

Chen J, Gao C, Zeng X et al., 2017. Assessing changes of river discharge under global warming of $1.5^{\circ} \mathrm{C}$ and $2^{\circ} \mathrm{C}$ in the upper reaches of the Yangtze River Basin: Approach by using multiple-GCMs and hydrological models. Quaternary International, 453: 63-73.

Chen X, Mo X, Hu S et al., 2017. Contributions of climate change and human activities to ET and GPP trends over North China Plain from 2000 to 2014. Journal of Geographical Sciences, 27(6): 661-680.

Cheng J W, Zhang Y X, 1996. Discussion on relation between humidity index and aridity degree. Journal of Desert Research, 16(1): 79-82.

Cong Z T, Ni G H, Yang D W et al., 2008. Evaporation paradox in China. Advances in Water Science, 19(2): 147-152. (in Chinese)

Cui Y P, Xiao D P, Liu S J et al., 2018. Growth periods variation of summer maize and winter wheat and their correlations with hydrothermal conditions in recent years in China. Chinese Journal of Eco-Agriculture, 26(3): 388-396. (in Chinese)

Djaman K, Komla G, 2015. Trend analysis in reference evapotranspiration and aridity index in the context of climate change in Togo. Journal of Water \& Climate Change, 6(4): 848-864.

Feng, S, Fu, Q, 2013. Expansion of global drylands under a warming climate. Atmospheric Chemistry and Physics, 13(19): 10081-10094.

Frieler K, Lange S, Piontek F et al., 2017. Assessing the impacts of $1.5^{\circ} \mathrm{C}$ global warming: Simulation protocol of the Inter-Sectoral Impact Model Intercomparison Project (ISIMIP2b). Geoscientific Model Development Discussions, 10(12): 1-59.

Fu Q, Feng S, 2014. Responses of terrestrial aridity to global warming. Journal of Geophysical Research Atmospheres, 119(13): 7863-7875.

Hao Z R, Guo W, He J Y et al., 2014. The variation tendency of surface aridity index of Shanxi province in recent 50 years. Agricultural Research in Arid Areas, 32(6): 244-249. (in Chinese)

Harris I, Jones P D, Osborn T J et al., 2014. Updated high-resolution grids of monthly climatic observations: The CRU TS3.10 Dataset. International Journal of Climatology, 34(3): 623-642.

Hempel S, Frieler K, Warszawski L et al., 2013. A trend-preserving bias correction: The ISI-MIP approach. Earth System Dynamics, 4(2): 219-236.

Huang H P, Han Y P, Cao M M et al., 2016. Spatial-temporal variation of aridity index of China during 1960-2013. Advances in Meteorology, 31(9): 1488-1498.

Huang J L, Wang Y J, Fischer T et al., 2017. Simulation and projection of climatic changes in the Indus River Basin, using the regional climate model COSMO-CLM. International Journal of Climatology, 37(5): $2545-2562$.

Huntington T G, 2006. Evidence for intensification of the global water cycle: Review and synthesis. Journal of Hydrology, 319(1): 83-95.

IPCC, 2013. Climate Change 2013: The Physical Science Basis. IPCC Working Group 1 Contribution to AR5. Cambridge. UK, New York, USA: Cambridge University Press.

IPCC, 2014. Climate Change 2014: Synthesis Report, in: Contribution of Working Groups I, II and III to the Fifth Assessment Report of the Intergovernmental Panel on Climate Change, IPCC Geneva, Switzerland, 151.

Jiang T, Wang Y J, Yuan J S et al., 2018. Projection of population and economy in "the Belt and Road" countries (2020-2060). Climate Change Research, 14(2): 155-164. (in Chinese)

Li F P, Zhang G X, Dong L Q et al., 2013. Studies for impact of climate change on hydrology and water resources. Scientia Geographica Sinica, 33(4): 457-464. (in Chinese)

Lin L, Gettelman A, Feng S et al., 2015. Simulated climatology and evolution of aridity in the 21 st century. 
Journal of Geophysical Research Atmospheres, 120(12): 5795-5815.

Liu F X, Wang Y J, Zhao J et al., 2017. Variations of the extreme precipitation under the global warning of $1.5^{\circ} \mathrm{C}$ and $2.0^{\circ} \mathrm{C}$ in the mid-lower reaches of the Yangtze River Basin. Resources and Environment in the Yangtze Basin, 26(5): 778-788. (in Chinese)

Liu W D, Song Z Y, Liu Z G et al., 2018. Progress in research on the Belt and Road Initiative. Acta Geographica Sinica, 73(4): 620-636. (in Chinese)

Liu X M, Zhang D, Luo Y Z et al., 2013. Spatial and temporal changes in aridity index in northwest China: 1960 to 2010. Theoretical \& Applied Climatology, 112(1/2): 307-316.

Lu M, Chen Y, Lu Y Q et al., 2018. The spatial balance pattern between land and sea transport in Europe-Asia under the Belt and Road Initiative. Acta Geographica Sinica, 73(8): 1526-1539. (in Chinese)

Meng M, Ni J, Zhang Z G, 2004. Aridity index and its applications in geo-ecological study. Acta Phytoecologica Sinica, 28(6): 853-861. (in Chinese)

Nastos P T, Politi N, Kapsomenakis J, 2013. Spatial and temporal variability of the Aridity Index in Greece. Atmospheric Research, 119(1): 140-152.

Oki T, Kanae S, 2006. Global hydrological cycles and world water resources. Science, 313(5790): 1068-1072.

Peterson T C, Golubev V S, Groisman P Y, 1995. Evaporation losing its strength. Nature, 377(6551): $687-688$.

Ponce V M, Pandey R P, Ercan S, 2000. Characterization of drought across climatic spectrum. Journal of Hydrologic Engineering, 5(2): 222-224.

Roderick M L, Rotstayn L D, Farquhar G D et al., 2007. On the attribution of changing pan evaporation. Geophysical Research Letters, 34: 251-270.

Schilling J, Vivekananda J, Nisha P et al., 2013. Vulnerability to environmental risks and effects on community resilience in mid-west Nepal and South-East Pakistan. Environment \& Natural Resources Research, 3(4): 1-19.

Schleussner C F, Lissner T K, Fischer E M et al., 2016. Differential climate impacts for policy-relevant limits to global warming: The case of $1.5^{\circ} \mathrm{C}$ and $2^{\circ} \mathrm{C}$. Earth System Dynamics, 6(2): 2447-2505.

Su B D, Huang J L, Gemmer M et al., 2016. Statistical downscaling of CMIP5 multi-model ensemble for projected changes of climate in the Indus River Basin. Atmospheric Research, 178/179: 138-149.

Su B D, Jian D N, Li X C et al., 2017. Projection of actual evapotranspiration using the COSMO-CLM regional climate model under global warming scenarios of $1.5^{\circ} \mathrm{C}$ and $2.0^{\circ} \mathrm{C}$ in the Tarim River Basin, China. Atmospheric Research, 196(11): 119-128.

Sun H M, Wang Y J, Chen J et al., 2017. Exposure of population to droughts in the Haihe River Basin under global warming of 1.5 and $2.0^{\circ} \mathrm{C}$ scenarios. Quaternary International, 453(9): 74-84.

Tabari H, Aghajanloo M B, 2013. Temporal pattern of aridity index in Iran with considering precipitation and evapotranspiration trends. International Journal of Climatology, 33(2): 396-409.

Türkeş M, 2003. Spatial and temporal variations in precipitation and aridity index series of Turkey. Mediterranean Climate - Variability and Trends, 181-213.

Wang A Q, Su B D, Wang Y J et al., 2017. Variation of the extreme minimum temperature events and farmland exposure under global warming of $1.5^{\circ} \mathrm{C}$ and $2.0^{\circ} \mathrm{C}$. Acta Meteorologica Sinica, 75(3): 415-428. (in Chinese)

Wang F, Ding J L, Wei Y, 2017. Analysis of drought characteristics over countries and regions of "The Belt and Road" in recent one hundred years. Journal of Geo-information Science, 19(11): 1442-1455. (in Chinese)

Wang L P, Wen M, Song J X et al., 2016. Spatial-temporal variation of aridity index during 1961-2014 in China. Journal of Natural Resources, 31(9): 1488-1498. (in Chinese)

Warszawski L, Frieler K, Huber V et al., 2014. The Inter-Sectoral Impact Model Intercomparison Project (ISI-MIP): Project framework. Proceedings of the National Academy of Sciences of the United States of America, 111(9): 3228-3232.

Yin Y H, Wu S H, Zheng D et al., 2005. Regional difference of aridity/humidity conditions changeover China during the last thirty years. Chinese Science Bulletin, 50(19): 2226-2233.

Zhang H L, Zhang Q, Liu Q et al., 2016. Analysis on variation characteristics and differences of the Climate drying degree between South and North of China. Plateau Meteorology, 35(5): 1339-1351. (in Chinese)

Zheng J Y, Bian J J, Ge Q S, 2013. The climate regionalization in China for 1981-2010. Chinese Science Bulletin, 58(30): 3088-3099.

Zheng J Y, Yin Y, Li B Y, 2010. A new scheme for climate regionalization in China. Acta Geographica Sinica, 65(1): 3-12. (in Chinese) 